\title{
North slope missile testing range: a role playing approach to photoinstrumentation education
}

\section{Andrew Davidhazy}

Andrew Davidhazy, "North slope missile testing range: a role playing approach to photoinstrumentation education," Proc. SPIE 2525, 1995 International Conference on Education in Optics, (13 October 1995); doi: $10.1117 / 12.224056$

SPIE Event: SPIE's 1995 International Symposium on Optical Science, Engineering, and Instrumentation, 1995, San Diego, CA, United States 
North Slope Missile Testing Range

- a role playing approach to photoinstrumentation education

\author{
Andrew Davidhazy \\ Rochester Institute of Technology \\ Imaging and Photographic Technology \\ 70 Lomb Memorial Drive, Rochester, NY 14623
}

\begin{abstract}
$\underline{\text { ABSTRACT }}$
The end of the cold war and the drastic downsizing of missile research along with the steady retirement of personnel versed in the technical aspects of missile performance evaluation through photographic processes have created a situation where the number of qualified individuals to provide such services is precariously low and where the technology itself is being forgotten.

At the Imaging and Photographic Technology Department at the Rochester Institute of Technology we are making a small effort to teach introductory concepts often taken directly from imaging technologies associated with missile range photography. These technologies involve near-miss analysis and basic photogrammetry, streak photography for measurements of velocity, acceleration and event duration, shadowgraph and schlieren imaging, high speed flash photography of explosive events, etc.
\end{abstract}

One of the methods by which a healthy dose of respect for traditional technology is taught is by setting up a mock missile range in the Department's High Speed laboratory. This project includes a missile firing control station, a photography section, a missile assembly area and other interdependent activities.

Students build their own rockets, are taught the fundamental principles related to synchroballistic photography, they become range "officers" and are never in charge of launching their own rocket and acquiring their own data but have to depend on their classmates to perform their assigned roles without error. Eventually the students then analyze the film data and report on the performance characteristics of their missiles.

It is the purpose of this paper to share with professional technologists one project that is part of the Imaging and Photographic Technology curriculum at RIT designed to help preserve the technologies which provided the foundation upon which SPIE itself was founded.

Key words: education, photography, synchroballistic, rocket photography, missiles, photoinstrumentation, range instrumentation, ballistic photography.

\title{
2. OBJECTIVES
}

It seems that it is important to give a brief introduction to the objectives of this program because the subject is not widely known. The field of technical photography is quickly becoming depleted of personnel who have an awareness of the procedures and techniques associated with a sub-specialty within the field, known as "photoinstrumentation". Somewhat liberally these people could be categorized as the rocket photographers of the 1950's to the 1970's. This is partly due to retirement of those who learned on-the-job and partly to the fact that the activity level in the area of ballistics photography has declined in recent years. Since details of the kind of problems and solutions which these photographers encountered were not well documented in the professional journals, the effect is that those who know are retiring without teaching those who don't. The outcome is a noticeable decrease in the number of competent and enthusiastic photoinstrumentation specialists. This has serious implications to the national defense effort in particular and to the field of applied photography in general.

To counteract this trend, I proposed to introduce into my curriculum in technical photography a simulation of the events, procedures and data reduction techniques associated with a simulated but very real ballistics experiment: the photography of a rocket in flight and subsequent evaluation of its performance. To this end, my objectives for this project were to impress on the students the importance of the photographic technician's role in the procurement of vehicle flight performance data and to appreciate and understand the function of instruments related to the procurement of this data. They were to show that they could use the equipment and analyze the results by the submission of written "mission reports" submitted at the conclusion of the project. 
A secondary objective designed primarily to increase the employability of the students was to make them aware, through participation in this simulation, of seldom apparent career and occupational possibilities beyond those associated with photography as a medium of visual expression.

\section{STUDENTS}

This program was designed for junior and senior level students enrolled in a required course in High Speed/Time Lapse Photography within the Imaging and Photographic Technology degree. This course provides the students with an overview of various high speed imaging tehcniques associated with photoisntrumentation. While the introductory nature of the course did not allow an in-depth mathematical treatment of the experiment, most of them were able to handle without great difficulty the mathematical concepts which were necessary for a preliminary approach to the problem. This was handled by first making sure that they understood the logic behind a relatively easily understood outcome to a problem and then encouraging them to manipulate the factors involved in such a manner that they could establish appropriate mathematical relationships.

\section{MATERIALS AND EQUIPMENT}

Each of the students built their own model rocket. While the intention was to fly them to their destruction at the end of their first (and only!) flight, we did manage to "catch" some and recover them in fairly good shape. The purpose behind the original intention was to hopefully elicit from the student extra care not only in how the rocket was built, but also on how it would be photographed. This in fact did happen and there were machines made that it was a shame to see smash into the ceiling above the false ceiling of the laboratory.

The instructor provided a suitable launch area in the laboratory and an appropriate velocity and spin measuring camera suitable for the acquisition of the necessary data. This consisted of an improvised drum-type synchroballistic camera built mostly of plywood and glue. Industrial cameras operating on the same principle cost upwards of $\$ 5,000$. In this simulation the fundamental principles behind the manner in which synchroballistic photographs are made could actually be better explained with the improvised camera than would have been possible with latest state-of-the-art equipment.

In its latest version, the camera consisted of a motorized rotating drum encased in a box which could be made light tight. A lens added to the box formed an image of the moving rocket onto the film which was attached emulsion out to the drum's surface. A slit was added between the lens and film, about $1 \mathrm{~mm}$. from the film's emulsion.

During photography, the drum with the film attached to it was set in motion and the rate was adjusted so that the film surface speed was approximately equal to the expected speed at which the image of the flying rocket would pass by the slit in the camera. Thus the film basically recorded a stationary image. Distortions in the final record can be interpreted as a mismatch between the speed of the film and the rocket's image. By analyzing the amount of distortion the speed of the actual rocket can be found. Since the moving film provides a time base, it is also possible to determine the velocity of the rocket by noting the length of its image on the film and dividing by film velocity. This stands for time elapsed from nosecone and tail assembly arrival at the slit and the length of the actual rocket divided by this time is the average rocket velocity between these two events.

A provision was made for students whose launch failed for some reason or other. They were provided with "generic" data created by the instructor beforehand but they did not know of this until after a given mission failure!

\section{STUDENT ACTIVITIES}

The students played an active role in this project almost from the beginning. During launch operations, the student whose rocket was being launched was designated "Mission Commander" and assumed full command of the range. Other students carried such titles as "Communications Officer", "Range Safety Officer", "Fire Control Specialist", "Chaplain", etc.

The student who was a "mission commander" for his/her own rocket's launch did not do his/her own photography. Mission Commanders were responsible for loading the special camera used for the project and were "in charge" of other students with differently designed duties to perform the actual launch and photography activities. As a "manager" in this capacity, the student was made to feel more responsible for understanding the procedures and processes that generated the required data. 
The class worked as a group on the improvised "range". In addition to the Mission Commander, there was a Photography Specialist in charge of monitoring the speed at which the drum in the camera was turning. When the camera was up to speed, the Launch Control Officer would check for missile firing continuity and on a positive result would initiate the Coundown process. Upon reaching "launch minus 2 seconds" the Illumination Section Head would turn on the high intensity light sources necessary to properly expose the film to the image of the missile as it flew in front of the camera. As the missile lifted off from Launch Pad ALPHA, it activated a microswitch which in turn triggered a one-shot timer for about $1 / 4$ second. The function of this timer was to open an electromagnetic shutter located directly in front of the camera lens before

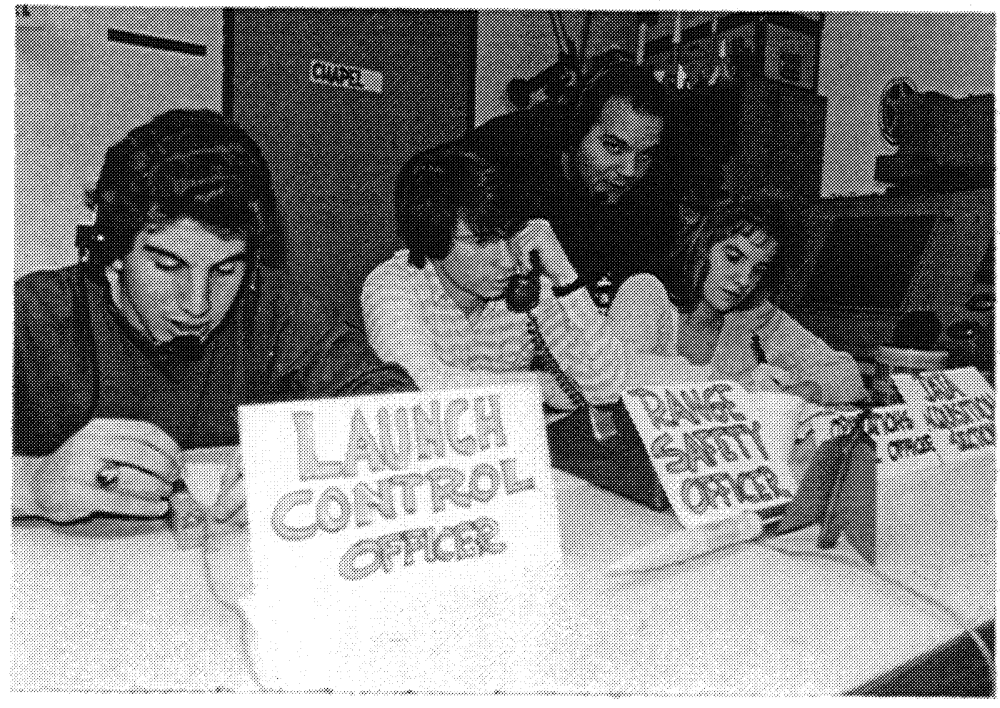
the missile reached the level of the camera and to close it as soon as possible after the missile had passed the exposure area in front of the camera. While this "capping shutter" is not an absolute necessity, it does prevent multiple exposure of the film should the missile fall back in front of the camera before the high intensity lights are turned off. The missile catcher was a $21 / 2$ foot diameter, 4 foot high galvanized tube installed on the false ceiling and the top end of it was closed with two layers of moist towels. The towels acted as shock absorbers for all the missiles but would also catch and hold those which pierced the soggy fabric.

As can be imagined, there was the share of rockets which failed to ignite at launch, or which ignited but got stuck on the launch rod, and those that missed the trap above and gave us a good scare as they zoomed around at floor height. As a result of participating in this experiment, each student prepared a written "mission report" summarizing the launch proceedings and an analysis of the data relative to the vehicle's velocity.
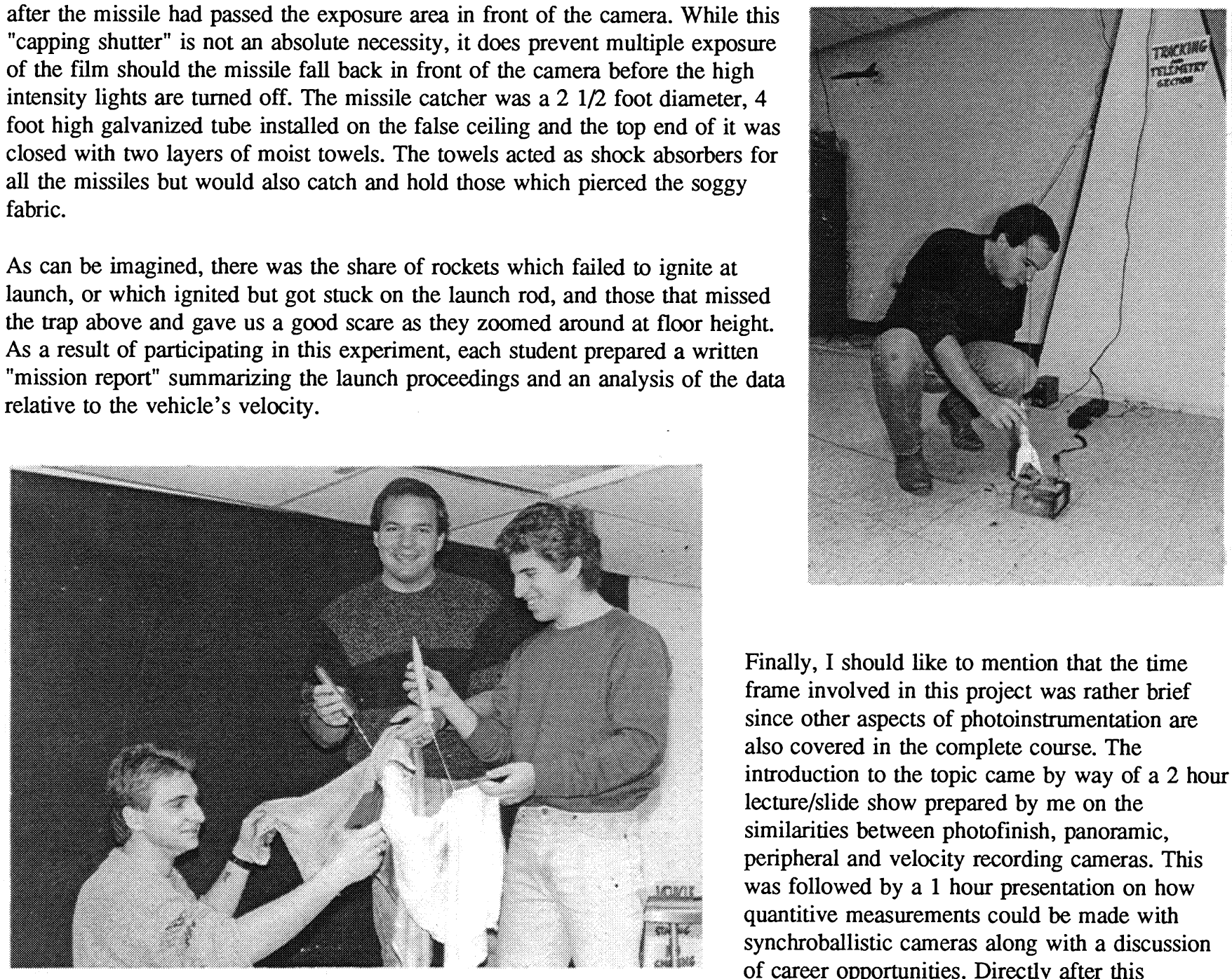

Finally, I should like to mention that the time frame involved in this project was rather brief since other aspects of photoinstrumentation are also covered in the complete course. The introduction to the topic came by way of a 2 hour lecture/slide show prepared by me on the similarities between photofinish, panoramic, peripheral and velocity recording cameras. This was followed by a 1 hour presentation on how quantitive measurements could be made with synchroballistic cameras along with a discussion of career opportunities. Directly after this 
presentation the laboratory portion of the project took place over a period of 4 hours during which time every student's rocket was launched at least once. Although a huge ventilating fan was installed in the laboratory the smoke and smell of gunpowder permeated the room as well as the building!

\section{ADAPTABILITY}

The project as envisioned seems very easily transferable to other disciplines, especially those related to instruction in the physical sciences. While the role of photography as a visual tool is well publicized, the potential of photographic methods as bonafide tools of scientific measurement are often not so readily recognized. A project like this could be approached from the physics end just as easily as from the technical photography end. In this case, we studied flight and motion but the study of time is the common thread.

\section{SAFETY}

As with any experiment that involves flames and high speed phenomena this one is not a project without risks. Anyone contemplating working with students and rockets would have to do so by weighing the risk factors associated with the project and making sure to take as many safety measures as possible. This paper is not an endorsement or encouragement for anyone to do this other than at their own risk.

\section{CONCLUSION}

The students will not forget this experience for a long time. Copies of reports submitted by the students can be made available to anyone interested in seeing them. A video tape of part of the launch proceedings is also available. The short range evaluation of this project seems to be that it was quite successful, not only from an instructional standpoint, but also in terms of an enthusiasm measure. The long range effects of this project will only become apparent when the students start to make career or employment choices, when their on-the-job performance can be evaluated and when they report back to the instructor and the institution on their level of job satisfaction and life goal fulfillment.

The success of the project's goals was assessed from the responses of the students which are included in the conclusions statements appended to their written "mission reports". In addition, the measurement concepts covered in the program were included in a short exam which was

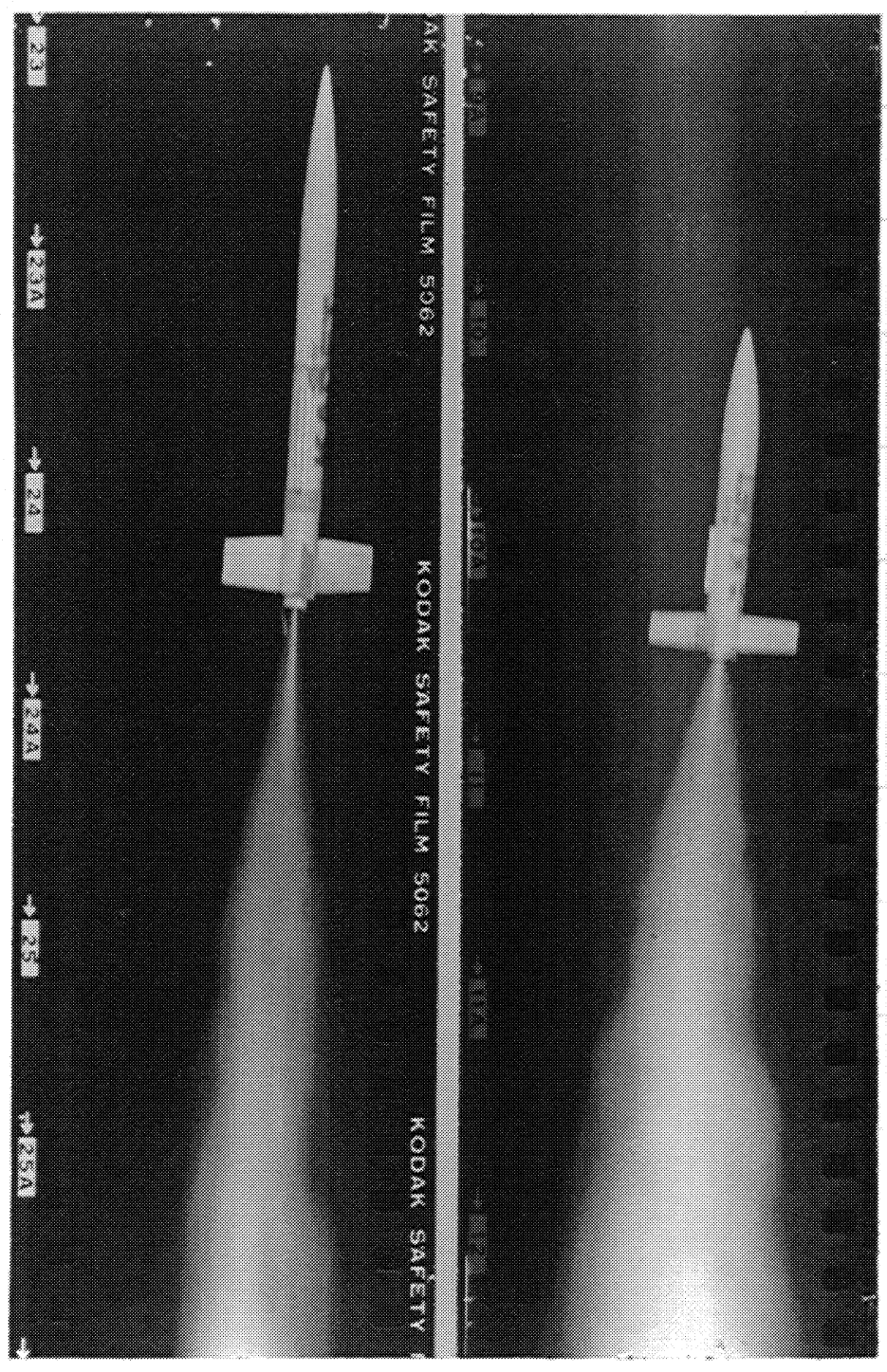
administered a week after the end of the program.

Based on the written reports and on student performance in relation to test questions about this topic, the outcome has to be labeled as being quite successful. Since this was the last project of the term, it helped wrap up the semester with a bang! 